\title{
O HORIZONTE SOCIAL DA LINGUAGEM: FUNDAMENTO BAKHTINIANO DA CONSTRUÇÃO CURRICULAR PARA ALÉM DA UNIVERSALIDADE BURGUESA
}

\section{THE SOCIAL HORIZON OF LANGUAGE: BAKHTINIAN BASIS ON THE CONSTRUCTION OF A CURRICULUM THAT TRANSCENDS BURGEOIS UNIVERSALITY}

\author{
Márcia Helena Sauaia Guimarães Rostas, Eliézer dos Santos Oliveira
}

Instituto Federal de Educação, Ciência e Tecnologia Sul Rio Grandense

E-mail:mrostas@hotmail.com, esantoliveir@gmail.com

\begin{abstract}
Resumo
Neste texto analisamos o currículo como discurso tomando por base o pensamento bakhtiniano. $\mathrm{O}$ interesse pela temática surge em um seminário do Mestrado Profissional em Educação e Tecnologia e dá impulso a uma investigação robusta da obra do autor e que respondesse as questões: o que é discurso? O que é linguagem? O que define a linguagem? Que compreensão de linguagem poderia fundamentar um currículo que fosse além da educação para o capital (cf. Mészàros). O aspecto central desta pesquisa - a descoberta do conceito de "horizonte social" robusto para fundamentar a crítica ao currículo burguês e forte para fundamentar uma contraproposta curricular. Por fim, através da desconstrução da ideia do currículo universal, com os seus programas educacionais, livros didáticos, parâmetros curriculares gerais, apresentamos a educação voltada para o mercado como a única, necessária e urgentemente possível. Embasados na concepção marxiano-bakhtiniana é possível construir um arsenal crítico capaz de combater a pretensa universalidade neutra, naturalizada, abstrata da filosofia da linguagem burguesa que esconde o "horizonte social" de suas palavras e signos em geral. Por mais que os ideólogos burgueses não queiram, seus discursos são situados num modelo econômico, num tempo histórico e numa classe social. Por isso, o alcance de suas falas não pode ser (e não é) considerado, numa perspectiva crítica, como universais. Elas nascem, reproduzem-se e resolvem-se num horizonte social concreto, material bem definido que determina o que será abordado e o que será silenciado. A linguagem do discurso curricular, ao tomar para si os horizontes sociais da classe dominada em luta pela sua libertação, irá edificar propostas curriculares que serão a expressão da negatividade dialética do macrossistema, contra-hegemônicas à totalidade histórica construída pelo capitalismo.
\end{abstract}

Palavras-chave: educação profissional e tecnológica. Institutos Federais de Educação. independência tecnológica. desenvolvimento social.

\begin{abstract}
In this paper we analyze the speech as curriculum building on the thought Bakthiniano. Interest in the issue arises at a seminar of the Professional Masters in Education and Technology, and gives impetus to a robust research of the author's work and to answer the questions: what is speech? What is language? What defines the language? Which comprehension a language could justify a curriculum beyond education to capital(see Meszaros). The central aspect of this research - the discovery of the concept of "social horizon" - substantiate the criticism of the bourgeois curriculum and strong justify for a curriculum counterproposal. Finally, through the deconstruction of the idea of the universal curriculum, with its programs educational, textbooks, general curricular
\end{abstract}


parameters, we present the education for the market as the only necessary and urgently as possible. Based upon in Marxist-Bakhtinian conception is possible to construct a critical arsenal capable of combating one alleged universality neutral, naturalized, summary of language philosophy that hides the "social horizon" of his words and signs in general. As much as the bourgeois ideologues not want, his speeches are situated in an economic model, on a historical time and to an social class. Therefore, the scope of their speech can not be (and is not) considered on a critical perspective, as universals. They are born, reproduce and resolve an social horizon concrete, well-defined material that addressed what will be and what will be muted. The language of curricular speech, a take each other for social class horizons dominated in the struggle for their liberation, will build curricular proposals that will be the expression of the dialectic negativity of macrosystem, the totality historical counter-hegemonic, constructed by capitalism.

Keywords: professional and technological education. Federal Institute of Education. technology undependence. social development. 


\section{INTRODUÇÃO}

O interesse pela obra "Marxismo e filosofia da linguagem: problemas fundamentais do método sociológico na ciência da linguagem", de Mikhail Bakhtin, surgiu por conta do Seminário denominado "Discurso Pedagógico" do Mestrado Profissional em Educação e Tecnologia do Instituto Federal Sul Rio-Grandense (IFSUL). O debate girava em torno da ideia de que currículo é discurso, e, portanto, tem relação direta com a linguagem. Porém, tal resolução gerou novos problemas: o que é discurso? O que é linguagem? O que define a linguagem? Que compreensão de linguagem poderia fundamentar um currículo que fosse além da educação para o capital (cf. Mészàros)? Para responder a esta última questão, buscamos entender, em Bakhtin, a linguagem em geral a partir do seu princípio sintético, o signo - tema do primeiro capítulo do trabalho.

Depois, no capítulo subsequente chegamos ao aspecto central desta pesquisa: a descoberta do conceito de "horizonte social" desenvolvido por Bakhtin. Tal conceito se mostrou robusto para fundamentar a crítica ao currículo burguês e, ao mesmo tempo, forte para fundamentar uma contraproposta curricular capaz de, dialeticamente, ver a educação a partir de outro lócus que não se pretenda falsamente universal - tal como o modelo burguês o é. O conceito de "horizonte social" materializa, historiciza, concretiza, contextualiza a linguagem para além de qualquer idealismo que as propostas de "horizonte de sentido" (Gadamer, por exemplo) propõem.

Por fim, no último capítulo, haverá a desconstrução da tentadora ideia de que há a linguagem, o signo, a palavra e, por sua vez, o currículo universal. Por debaixo de tal universalidade esconde-se a particularidade burguesa, que pretende, com os seus programas educacionais, livros didáticos, parâmetros curriculares gerais, apresentar a educação para o mercado como a única, necessária e urgentemente possível.

\section{SIGNO: O PRINCÍPIO SINTÉTICO}

O currículo é basicamente discurso. Não um discurso reduzido a mero sopro de voz, algo abstrato, ideal, desvinculado do horizonte social do qual provém. Disso emerge o mérito de nosso autor, M. Bakthtin (1895-1975), o primeiro pensador a perceber, explicitamente, o caráter sociológico da linguagem, tal como evidencia no subtítulo da obra que tomamos como referência: "Problemas fundamentais do método sociológico na ciência da linguagem". Além deste grande feito, que 
marcaria os estudos posteriores de linguagem, ele também evidencia o seu caráter precursor ao promover, de forma original, a relação entre "marxismo e filosofia da linguagem", tal como expressa no título.

Nesta obra, Bakhtin não deixa nada do materialismo histórico e nem da dialética marxiana de fora. Ele consegue contemplar estas realidades materiais, históricas e dialéticas no que diz respeito a sua compreensão da linguagem. Para ele, os dualismos - entre universal e particular, social e individual, coesão e divisibilidade, diálogo e monólogo, signo e significação, linguagem e sociedade, comunicação verbal e não-verbal, fala e comunicação.- são falsos dualismos, uma vez que uns são indissociáveis dos outros. Por isso, Bakhtin considera a totalidade do modo de vida social composta por uma gama de valores sociais contraditórios e por uma estrutura social conflitiva impregnada pelas relações de dominação, resistência e adaptação.

Tal complexidade deverá fazer-se presente na construção curricular. Sem ela o currículo será reduzido às simplificações subjetivantes ou objetivantes. Estas evidenciam uma parte do real, tal como se a parte fosse o todo, ignorando totalmente a polaridade oposta. Seria bem mais fácil tomar a linguagem (o discurso, o signo, a palavra, o currículo) como algo que fosse apenas subjetivo, ou apenas objetivo, pois com isso, num caso jogaria tudo nas costas do sujeito, e noutro caso relegaria tudo à objetividade.

Bakhtin, ao contrário de tais simplismos, não se alinha nem a um lado e nem ao outro. Ele renuncia os posicionamentos acadêmicos exigidos pelo marxismo positivista estalinista e também recusa a simplificação do mecanicismo determinista, rejeitando assim, as tendências que colocam a objetividade sobre a subjetividade. De outro lado, ele não descamba para os formalismos apriorísticos, que primam pela subjetividade sobre a objetividade. Seu texto desenvolve a crítica ao subjetivismo individualista ${ }^{1}$ e ao mesmo tempo critica o objetivismo abstrato $^{2}$, sem ceder a um meio-termo eclético que enjambrasse os dois. O que Bakhtin faz é superar tal contradição de forma verdadeiramente dialética.

\footnotetext{
${ }^{1}$ Língua atividade criativa do indivíduo, criada pela psicologia individual como criação artística, a gramática é o sistema estável desta criação - cf. BAKHTIN, 2006, p.72-73.

${ }^{2}$ Língua sistema estável e imutável, com leis linguísticas específicas e objetivas impostas a toda consciência individual, sem relação com os valores ideológicos, atos individuais deformações da forma normativa - cf. BAKHTIN, 2006, p. 8283
} 
Acreditamos que aqui como em qualquer lugar a verdade não se encontra exatamente no meio, num compromisso entre a tese e a antítese; a verdade encontra-se além, mais longe, manifesta uma idêntica recusa tanto da tese como da antítese, e constitui uma síntese dialética (BAKHTIN, 2006, p. 111).

Bakhtin demonstra que a burguesia foi incapaz de solucionar a questão entre psicologia (interior) e ideologia (exterior) numa síntese dialética, chegando, no máximo, à condição de alternância entre uma e outra (cf. BAKHTIN, 2006, p.56). O mesmo acontece na educação que ora foca na realidade objetiva, esquecendo-se das subjetividades (os autores estruturalistas são um bom exemplo disto, visto centrarem-se na reprodução social), ora esquecendo-se da objetividade (algo bastante atual, sobretudo devido ao processo de psicopedagogização da escola: laudos, alunos especiais... que perdem o meio de vista). Tanto a objetivação quanto a subjetivação da educação passa pela compreensão curricular, construída pelo discurso dos agentes que compõem a comunidade escolar.

Bakhtin, ao contrário da polarização pendular, se põe a pensar os contraditórios em sua unidade dialética. Nesta o subjetivo se dissolve na objetividade da enunciação e a palavra enunciada se subjetiva no indivíduo que a pronuncia. Assim, a palavra emerge como o lócus onde a psicologia e a ideologia se (inter)penetram, formando assim, o processo do entrecruzamento das lutas entre valores sociais contraditórios. A partir disto a filosofia da linguagem de Bakhtin se transforma na

[...] filosofia do signo, a filosofia da palavra, enquanto signo ideológico por excelência. O signo ideológico é o território comum, tanto do psiquismo quanto da ideologia; é um território concreto, sociológico e significante. É sobre este território que se deve operar a delimitação das fronteiras entre a psicologia e a ideologia (BAKHTIN, 2006, p. 56).

Com isto Bakhtin não rejeita e nem absolutiza a enunciação do ato de fala individual e, de outro lado, também não rejeita e nem absolutiza o sistema linguístico como critério determinante dos fatos da língua. Com isso, se contrapõe à solução idealista que afirma a língua como produto da ação livre, racional, subjetiva, psicológica, consciente de indivíduos que constituem significados; e 
ao mesmo tempo combate os que concebem a língua como um fato social empírico, exterior, coercitivo, determinado por normas exteriores ao indivíduo. A síntese dialética de Bakhtin contempla ao mesmo tempo a organização social e a (inter)ação dos sujeitos envolvidos:

Todo signo, como sabemos, resulta de um consenso entre indivíduos socialmente organizados no decorrer de um processo de interação. Razão pela qual as formas do signo são condicionadas tanto pela organização social de tais indivíduos como pelas condições em que a interação acontece (BAKHTIN, 2006, p. 43).

Assim as relações entre organização social (infraestrutura) e signo (superestrutura) não são unilaterais, nem mecânicas, nem determinísticas, mas sim dialéticas, complexas, mútuoimplicadas. A alteração de uma implica modificações na outra e vice-versa. Por isso, somente levando em conta esta totalidade da evolução social é que se torna possível articular o signo ao ser e o ser ao signo.

Só esta abordagem pode dar uma expressão concreta ao problema da mútua influência do signo e do ser; é apenas sob esta condição que o processo de determinação causal do signo pelo ser aparece como uma verdadeira passagem do ser ao signo, como um processo de refração ${ }^{3}$ realmente dialético do ser no signo (Ibidem).

Por isso, se a Escola quer, de fato, construir um currículo que expresse a realidade concreta da educação, ela não poderá se refugiar no mundo das ideias (superestrutura ideológica) e nem restringir-se às análises economicistas. Um currículo que parta do todo complexo, enfrente a gama de interesses contraditórios colocados na luta de classes, resultará num currículo dialético, manifesto tanto no ser social material quanto no signo (ideal) fecundado por tal concretude. Em outras palavras, o currículo não será algo somente ideal (existente no âmbito das ideias) e não somente material (existente no âmbito da materialidade histórica), mas em ambos e mutuamente relacionados. Será o currículo presente nas relações entre o sujeito e o meio, o ser e o pensar, a base material da sociedade e suas representações. 
A fim de garantir as condições metodológicas desta síntese Bakhtin apresenta três condições metodológicas indispensáveis que servem tanto para a linguagem, quanto para o discurso, quanto para o currículo.

1. Não separar a ideologia da realidade material do signo (colocando-a no campo da "consciência" ou em qualquer outra esfera fugidia e indefinível). 2. Não dissociar o signo das formas concretas da comunicação social (entendendo-se que o signo faz parte de um sistema de comunicação social organizada e que não tem existência fora deste sistema, a não ser como objeto físico). 3. Não dissociar a comunicação e suas formas de sua base material (infra-estrutura) (Ibidem).

Assim, Bakhtin consegue ser fiel ao materialismo histórico de Marx. Ele toma o signo como fruto da totalidade histórica contraditória (portanto dialética) formada por grupos sociais que o disputam, material e ideologicamente, entre si. Com isto não nega o papel dos indivíduos, que aparecem desde sempre uns em relação aos outros, no meio social, produzindo signos com significações sociais reconhecidas pelas relações sociais e não de forma apriorística, nem formalista ou voluntarista.

Tais indivíduos são, desde sempre, situados numa materialidade histórica, socialmente constituída, a partir da qual formam a sua psique, filha das relações dialéticas entre materialidade e idealidade. Por isso esta produção somente é possível a partir da realidade social, visto que a própria consciência emerge e se afirma como tal por meio dos signos.

A significação (...) é resultado, antes de mais nada, de uma disputa ideológica entre grupos sociais distintos, com perspectivas ideológicas distintas, ditadas objetivamente pela situação concreta em que se encontram os grupos sociais e subjetivamente pela visão-social-de-mundo que comportam seus sujeitos (CRUZ, 2000, p.27-28).

M. Bakhtin não pensa um ser humano pré-social, "virgem" de signos, mas sim como um ser social que compreende a realidade de signo em signo, relacionando um com os outros, numa totalidade,

\footnotetext{
3 "O que é que determina esta refração do ser no signo ideológico? O confronto de interesses sociais nos limites de uma só e mesma comunidade semiótica, ou seja: a luta de classes." (BAKHTIN, 2006, p. 45)
} 
a partir da qual, ele (indivíduo) até mesmo pode criar alguns signos de outros. Deste modo, a consciência não é vista como algo que se encontra acima da existência (transcendente) - tal como pretendia o idealismo - e nem se situa numa mera reação (psico)fisiológica (natural) fortuita diante da linguagem supra-humana - tal como pretendia o positivismo.

Na perspectiva bakhtiniana, a consciência pura não existe, desde sempre ela é carente de comunicação ideológica, interação social, conteúdo semiótico: imagem, palavra, gesto... "A consciência individual não é o arquiteto dessa superestrutura ideológica, mas apenas um inquilino do edifício social dos signos ideológicos" (BAKHTIN, 2006, p. 34).

Ao situar o signo como o espaço de disputa ideológica, Bakhtin, não o compreende como pronto, mas como algo a ser construído de forma viva, móvel, evolutiva, conflitiva e contraditória (social). Uma comunidade semiótica, que utiliza o mesmo código de comunicação (língua), é atravessada pelas disputas das classes sociais que lutam para imprimir os seus valores aos signos. Por isto, o signo é a síntese dialética que reúne tudo em si: a realidade material, a língua, as relações interindividuais, as classes sociais, o meio ideológico, a formação da consciência, a lógica da comunicação, a criação do novo a partir do velho, etc.

Tal compreensão reconhece a linguagem (e por sua vez o currículo) como um território cheio de contradições de classe, conflitos raciais, tensões de gênero... e todos os demais impasses e disputas que a história venha a gerar e que os sujeitos históricos elaborarem. Por isso, (cf. SILVA, 2010) o machista e a feminista, o eurocêntrico e o multiculturalista, o opressor e o oprimido, o homofóbico e o homoafetivo, o colonizador e o colonizado estarão disputando entre si o signo, a partir do qual construirão os seus discursos e com eles, a legitimação de determinado currículo contra outra compreensão discursiva-curricular.

Por isso é falsa a dicotomia entre interioridade e exterioridade, psiquismo e ideologia, visto que o signo é a síntese capaz de superar, e desmascarar a falsidade destas polarizações.

O signo ideológico tem vida na medida em que ele se realiza no psiquismo e, reciprocamente, a realização psíquica vive do suporte ideológico. A atividade psíquica é uma passagem do interior para o exterior; para o signo ideológico, o 
processo é inverso. O psíquico goza de extraterritorialidade em relação ao organismo. É o social infiltrado no organismo do indivíduo. E tudo que é ideológico é extraterritorial no domínio sócio-econômico, pois o signo ideológico, situado fora do organismo, deve penetrar no mundo interior para realizar sua natureza semiótica. Desta maneira, existe entre o psiquismo e a ideologia uma interação dialética indissolúvel: o psiquismo se oblitera, se destrói para se tornar ideologia e vice-versa. O signo interior deve libertar-se de sua absorção pelo contexto psíquico (biológico e biográfico), ele deve parar de ser experimentado subjetivamente para se tornar signo ideológico. O signo ideológico deve integrarse no domínio dos signos interiores subjetivos, deve ressoar tonalidades subjetivas para permanecer um signo vivo e evitar o estatuto honorífico de uma incompreensível relíquia de museu (BAKHTIN, 2006, p. 64).

Deste modo, é impossível reduzir o signo (o discurso, a palavra, o currículo) ao interior (psique) quanto ao exterior (ideologia), visto que ele opera e transita em ambas as dimensões, colocandoas uma em relação com a outra. Só assim o signo cumpre a sua missão e se realiza como tal. O mesmo ocorre com o currículo: um currículo apenas exteriorizado jamais se realizaria nos sujeitos, não seria vivenciado, se tornando comparável a um estatuto morto, não assumido por ninguém; ou ainda, seria um currículo apenas interiorizado, vivido na intimidade de cada um, sem jamais se objetivar no mundo, seria como um fantasma (uma alma sem corpo social), sem existência efetiva na realidade material (no mundo humano), algo sepultado no interior do indivíduo.

Dentre todos os signos Bakhtin destaca a palavra como o signo por excelência por conta de sua utilização na comunicação cotidiana. Além disto, a palavra, por ser o modo mais puro, básico e formal mantém um vínculo direto com a relação social, sendo por isto o lócus onde a ideologia é revelada de forma mais explícita e abrangente. A palavra difere-se dos outros signos cujas existências estão presas a um determinado campo específico da criação ideológica, ou seja, eles não possuem aplicações capazes de transcender o campo particular de seu domínio. Ao contrário disto, a palavra, por conta de sua abstração, é aplicável a qualquer campo seja ele qual for: estético, cultural, moral, religioso, científico, educacional, etc.

De outro lado, na cotidianidade a palavra não é percebida como portadora de ideologia, isto porque nem mesmo é percebida como palavra. O falante, em sua prática comunicativa diária não 
mantém a consciência de que a palavra pertence a um sistema linguístico normativo, para ele a palavra não pertence ao dicionário ou à gramática, quanto mais perceberá a ação do sistema ideológico na linguagem.

Na realidade, não são palavras o que pronunciamos ou escutamos, mas verdades ou mentiras, coisas boas ou más, importantes ou triviais, agradáveis ou desagradáveis, etc. A palavra está sempre carregada de um conteúdo ou de um sentido ideológico ou vivencial. É assim que compreendemos as palavras e somente reagimos àquelas que despertam em nós ressonâncias ideológicas ou concernentes à vida (BAKHTIN, 2006, p. 96).

Com isto, Bakhtin demonstra o quanto as palavras não são objetos tratáveis apenas pela abordagem linguística. As palavras, como qualquer outro material semiótico, são processos sociais (e não estruturas) que somente podem ser conscientemente compreendidas, em seus movimentos, pela relação interdisciplinar entre filosofia, sociologia, psicologia e linguística. A ciência social, sem remontar o horizonte social determinado desde onde emergiu um signo (palavra) específico, estará impossibilitada de compreendê-lo, visto que sem tal horizonte sequer existe signo.

Assim sendo, torna-se impossível compreender determinado currículo (ou determinado discurso curricular, ou ainda sobre o currículo) se o horizonte social determinado originário for desconhecido de quem pretende falar e/ou ouvir dele e sobre ele. 


\section{HORIZONTE SOCIAL}

Uma vez identificada a contradição fundamental entre interior (psiquismo) e exterior (ideologia) e a sua superação no princípio sintético do signo (e da palavra como signo por excelência) é possível agora partir para a análise do sentido e do lugar que a expressão bakhtiniana "horizonte social" ocupa em sua obra "Marxismo e Filosofia da Linguagem".

Tal como já foi tratado, para M. Bakhtin não existe sujeito, nem linguagem, nem signo (por consequência, nem palavra) e, em nosso caso, nem currículo... sem contexto social. Nenhum deles é um ente transcendente, puro, ensimesmado, natural, abstrato... pelo contrário, cada um deles é, desde sempre, marcado pelo seu horizonte social. Esta determinação do horizonte social define o alcance e o limite da visão de mundo do sujeito histórico participante do diálogo social, inclusive quando faz de si mesmo o seu próprio interlocutor. Até o diálogo interior, conversar consigo mesmo, expressa, por conta da linguagem, o contexto social.

O horizonte social é ao mesmo tempo o ponto de partida (de onde retira os elementos) e o ponto de chegada (para quem se dirige) da fala. Isso não pode ser confundido como a mera reprodução interior do que ocorre na exterioridade e nem como mera exteriorização do que se passa na interioridade. Há neste ínterim, tal como fora demonstrado anteriormente, um processo de reelaboração capaz de criar o novo a partir do velho, o individual a partir do social e vice-versa.

Assim, "realizando-se no processo da relação social, todo signo ideológico, é portanto também o signo lingüístico, vê-se marcado pelo horizonte social de uma época e de um grupo social determinados" (BAKHTIN, 2006, p. 43). Assim, o horizonte social é determinado pelo tempo histórico - com todas as condições sócio-econômicas que compõe a totalidade (o exteriorinteriorizado) - e pelos grupos que disputam a valoração interindividual dos signos (o interiorexteriorizado) (cf. BAKHTIN, 2006, p. 44). “Em outras palavras, não pode entrar no domínio da ideologia, tomar forma e aí deitar raízes senão aquilo que adquiriu um valor social" (BAKHTIN, 2006, p. 44).

Com isto, se tem a relação dialética que não permite as separações, para além da mera necessidade abstrata de distinção, entre interior e exterior. No processo social, ambos os momentos são indissociáveis, uma vez que o horizonte social que origina as formas de 
comunicação ideológica é o mesmo horizonte que permite a incorporação de um elemento novo nesta mesma realidade comunicativa. O movimento de transformação do horizonte social pode ser percebido pelas transformações, que este provoca, nos signos (sobretudo na palavra - por ser o signo por excelência), e por isso registram as alterações que ocorrem na realidade social - numa mútua implicação. Ao mesmo tempo em que o signo é alterado pela transformação do horizonte social ele oferece o diagnóstico de que o mesmo sofrera mudanças, e ainda, de que ele próprio transforma tal horizonte (cf. BAKHTIN, 2006, p.45).

Desta forma, a comunicação somente se torna possível graças ao horizonte social desde onde se fala, pois entre um falante e outro (interlocução externa) ou entre o indivíduo e o seu interior (diálogo interno) situa-se o meio social que permite e determina os limites, os alcances e as formas como tal interlocução ocorre.

Como consequência disto se tem que "não pode haver interlocutor abstrato; não teríamos linguagem comum com tal interlocutor, nem no sentido próprio nem no figurado" (BAKHTIN, 2006, p. 114). Ou seja, para a filosofia marxista da linguagem de Bakhtin não pode existir um sujeito sem mundo, tal como não há, no teatro, personagem sem contexto cênico (cenário, figurino, maquilagem...). Este contexto extra-palavra marca o horizonte social a partir do qual a palavra emergirá. "De maneira semelhante, quando reconhecemos uma personagem cômica no palco por seu estilo de maquilagem, sua roupa e sua atitude geral, já estamos prontos a rir mesmo antes de apreender o sentido de suas palavras" (BAKHTIN, 2006, p. 170). Assim, sem os atos sociais nãoverbais que marcam o horizonte social da palavra, ela mesma se torna inviável.

A comunicação verbal não poderá jamais ser compreendida e explicada fora desse vínculo com a situação concreta. A comunicação verbal entrelaça-se inextricavelmente aos outros tipos de comunicação e cresce com eles sobre o terreno comum da situação de produção. Não se pode, evidentemente, isolar a comunicação verbal dessa comunicação global em perpétua evolução (BAKHTIN, 2006, p. 126).

O horizonte social (temporal, espacial, econômico, ideológico, moral, científico, filosófico, religioso, jurídico, artístico...) constrói um auditório social (um interlocutor geral) que delimita as fronteiras 
do dizível e do indizível; do que pode e do que não pode ser transformado. Isto não equivale ao conservadorismo positivista negador das transformações da ordem estabelecida e nem à ingenuidade idealista afirmadora da condição ilimitada da racionalidade capaz de por si mesma moldar o mundo.

Com isto M. Bakhtin não nega que as ideias possam transformar a realidade, porém, para isto, as mesmas devem partir da realidade social, passar pela ação dos grupos sociais e dirigir-se para a realidade histórica. Segundo ele, meras atividades mentais não apresentam qualquer expressão de materialização por não possuírem um auditório social determinado que possa efetivá-las e por isto não apresentam as condições históricas de ganhar existência histórico-social.

Na nossa opinião, o que pode, na melhor das hipóteses, ser explicado por esse tipo de argumento sobre as motivações do falante, é meramente o uso em uma ou outra concreta ocorrência de uma forma já existente, mas em nenhuma circunstância poderá explicar a criação de uma nova forma lingüística. A expressão plena e íntegra das motivações e intenções do falante é limitada, de um lado, pelas possibilidades gramaticais efetivas, e de outro, pelas condições da comunicação sócio-verbal predominantes num determinado grupo. Essas possibilidades e condições são dadas, e delimitam o horizonte lingüístico do falante. Ele não poderia por si só alargá-lo (BAKHTIN, 2006, p. 180).

Ou seja, para Bakhtin não há como divorciar a linguagem da evolução social, nem tomá-la como se ela fosse uma realidade "em si mesma", coisificada, isolada de todo o resto da totalidade histórica.

A explicitação de uma relação entre a infra-estrutura e um fenômeno isolado qualquer, destacado de seu contexto ideológico completo e único, não apresenta nenhum valor cognitivo. Antes de mais nada, é impossível estabelecer o sentido de uma dada transformação ideológica no contexto da ideologia correspondente, considerando que toda esfera ideológica se apresenta como um conjunto único e indivisível cujos elementos, sem exceção, reagem a uma transformação da infraestrutura (BAKHTIN, 2006, p. 38). 
Assim, a significação e a própria mudança de significação deve passar pelos horizontes sociais existentes. Nada impede que um signo seja reavaliado que sofra transformações, entretanto, para isto, é preciso que exista outro horizonte social para o qual se desloque e possa ser apreciado de modo diverso (cf. BAKHTIN, 2006, p.138-139).

Coerente com o materialismo histórico de Marx, Bakhtin situa estes horizontes apreciativos dos diferentes grupos sociais na determinação originada pela expansão da base econômica da sociedade. Na mesma medida que a infraestrutura material da sociedade evolui, também os horizontes sociais se dilatam comportando elementos que anteriormente lhe eram estranhos. $\mathrm{O}$ exemplo que Bakhtin oferece é aquele que compara as preocupações, sentimentos, falas... do criador de gado do período pré-histórico com as preocupações, sentimentos, falas... do criador de gado capitalista. Este último apresenta uma série de compreensões sobre a existência e sobre a criação de gado que ultrapassam aquelas que eram necessárias ao homem pré-histórico.

Esse alargamento do horizonte apreciativo efetua-se de maneira dialética. Os novos aspectos da existência, que foram integrados no círculo do interesse social, que se tornaram objetos da fala e da emoção humana, não coexistem pacificamente com os elementos que se integraram à existência antes deles; pelo contrário, entram em luta com eles, submetem-nos a uma reavaliação, fazem-nos mudar de lugar no interior da unidade do horizonte apreciativo. Essa evolução dialética reflete-se na evolução semântica. Uma nova significação se descobre na antiga e através da antiga, mas a fim de entrar em contradição com ela e de reconstruí-la (BAKHTIN, 2006, p. 139).

Com isto Bakhtin demonstra que o horizonte social determina a linguagem e na medida em que ele se expande no processo histórico também a transforma e sofre as consequências das suas transformações.

Assim, há entre horizonte social e linguagem uma mútua implicação que não deixa nada no repouso parmenediano (isso prova que não se trata de uma estrutura), mas é a própria fluidez da dialética heraclitiana (é um processo, movimento): 
Não há nada na composição do sentido que possa colocar-se acima da evolução, que seja independente do alargamento dialético do horizonte social. A sociedade em transformação alarga-se para integrar o ser em transformação. Nada pode permanecer estável nesse processo (BAKHTIN, 2006, p. 139).

Num outro exemplo Bakhtin reconhece que o processo de simplificação do mundo do trabalho é capaz de simplificar a linguagem. Ele ilustra isto a partir do mundo dos negócios, marcado por relações meramente técnicas, que exigem formas de comunicação breve com perguntas e respostas curtas. Assim a etiqueta do bem-falar acompanha as relações sócio-produtivas ao mesmo tempo em que as possibilita.

A partir disto tudo é possível afirmar que aquele que não conhece o horizonte social mais amplo no qual a linguagem foi gerada, não é capaz, por mais que estude as questões específicas da linguagem em si, de compreendê-la. Isto porque a linguagem é antecedida, nasce, têm em si e expressa o horizonte social determinante de suas potencialidades e limites; e ao mesmo tempo ela própria, juntamente com outros fatores da totalidade histórica, é capaz de criativamente gerar, a partir do material disponível, novos horizontes sociais.

Tal relação, entre ser e signo, se mantém escondida por conta dos esforços que todas as classes dominantes dispensaram na história a fim de esconder, sob o manto da universalidade, o seu interesse social. Interessa à classe dominante de cada período histórico, mostrar a linguagem como algo formal, desvinculado do mundo material; alguma coisa, portanto, que não manifesta nada das relações sócio-materiais das classes entre si.

Por fim, vale o alerta contra as interpretações pós-modernas que Bakhtin poderá sofrer. Ao se referir ao "horizonte social da linguagem" ele não está tratando de horizontes fragmentados, tal como se cada grupo social tivesse o seu horizonte específico. Por mais que os sujeitos sejam diferentes (homoafetivos, homens, mulheres, negros, brancos, opressores, oprimidos...) todos se encontram no mesmo mundo, na mesma realidade, na mesma totalidade histórica da qual participam e com a qual, com suas inter-relações, constroem suas visões de mundo. Segundo Antônio Cruz (2000, p.33), isto caracteriza a filosofia da linguagem de Bakhtin: “(...) o fato é que 
nosso lingüista russo foi marxista, nos parece, no sentido em que Lukács defendia o marxismo ortodoxo: sustentar antes de tudo a categoria da totalidade histórica".

Por isso, os horizontes sociais da linguagem não se encontram soltos, tal como se os diferentes horizontes não se encontrassem, dialeticamente, articulados numa totalidade. Por isso, pode-se dizer que o horizonte social da classe dominante e o horizonte social da classe dominada, por mais diferentes que sejam, participam da mesma totalidade histórica. A história dos dominados e dos dominantes é a mesma, porém com versões diferentes segundo o horizonte social (concreto) que cada uma ocupa neste todo.

Com isso, pode-se dizer, que sem o conhecimento da totalidade histórica concreta e atual, não há como a ciência social entender a linguagem, o signo, a palavra, o discurso, o currículo. A particularidade, o fragmento, diz, indiretamente, algo do todo, visto que ela só é parte num todo. Porém, ao se absolutizar a parte e tratá-la como isolada da totalidade que the deu origem, que a sustenta e que constituí o seu fim, ela perde o sentido de ser aquilo que ela pretende ser, apenas uma parte. Ou seja, ela falseia a si mesma.

Diante disto cabe a crítica bakhtiniana contra as teorias pós-críticas (cf. SILVA, 2010, p.17) que buscam a diferença, a subjetividade, o micro, o multi, tomados como elementos independentes deste todo, que é material, histórico e complexo. Por isso, para pensar o currículo a partir do horizonte social da linguagem (do signo, da palavra), é mais necessário (à compreensão da totalidade histórica) o atual grau de desenvolvimento histórico (material-ideológico) do que, propriamente, entender cada pequeno grupo dentro deste movimento histórico mais amplo.

Por exemplo: se determinada escola constrói o seu currículo preocupada unicamente com a questão de gênero, sequer irá compreender a questão de gênero, visto que é incapaz de situar a sua questão no todo. Ou seja, é impossível entender a questão de gênero (e qualquer outra: cultural, étnica, religiosa...) fora das relações que compõem a totalidade histórica.

De outro lado, não se pode pensar que uma determinada totalidade histórica não tenha, em si, contradições, impasses, visões de mundo diferentes, ideologias contrapostas... Tal como já foi apresentado, há diferentes horizontes sociais concretos (e não meramente o horizonte de sentido 
de Gadamer, que não leva em conta a luta de classes), que por mais diferentes que sejam (e são!) de uma classe para a outra, se encontram juntos, de forma dialética, numa mesma totalidade histórica.

O horizonte social delimita o quanto há de determinação e liberdade, resistência e dominação, reprodução e crítica... em cada um dos momentos históricos. Por isso, tal como afirmam Marx e Mészáros, a educação feudal serviu ao feudalismo, a educação burguesa ao capitalismo... visto que a totalidade histórica confere o sentido do ser da educação, manifestando-o, segundo Bakhtin, no signo. Ou seja, os signos utilizados na educação feudal (burguesa...) têm seu sentido último dado pelo sistema sócio-material no qual eles se encontram.

No momento em que começam a surgir as primeiras palavras de contestação do Antigo Regime, e surgem as primeiras experiências de escolas burguesas, tais transformações já denotam a ampliação da totalidade histórica. Esta ampliação do horizonte, por sua vez, passa a oferecer uma oportunidade histórica nova, que até então inexistia. Ou seja, entra no horizonte concreto da história algo que, a princípio, ali não estava e que passa a se manifestar na linguagem.

Portanto, cabe nas reflexões acerca do currículo perguntar-se:

Quais são os limites de nosso horizonte social que delimitarão os limites de nossa linguagem? 0 que a totalidade histórica, na qual nos encontramos, nos possibilita e impossibilita? Sobre que transformações conseguimos discursar? Como as diversas vítimas desta totalidade histórica poderão superar estas condições que Ihes vitimizaram? Que sentido, à luz do horizonte social da totalidade histórica, têm os termos utilizados nos debates curriculares? Como cada classe social pronuncia, pela linguagem, tal horizonte social?

O próximo capítulo demonstrará como a classe dominante pretende pronunciar a totalidade histórica de forma universal, tal como se a sua linguagem pudesse dar conta da totalidade de forma neutra, objetiva e imparcial. A filosofia da linguagem burguesa pretende colocar-se num lugar impossível, que esteja fora do contexto social, ou seja, para além do lugar concreto a classe burguesa ocupa no todo com todos os seus interesses materiais. Os capitalistas, na disputa pelo 
signo, mostram-se como se não estivessem disputando-o, mas apresentam-se como se tivessem o signo universal.

\section{A UNIVERSALIDADE DA FILOSOFIA DA LINGUAGEM BURGUESA}

Bakhtin denuncia a falsa universalidade produzida pela classe dominante, no caso do capitalismo, produzida pela ideologia dominante expressa na filosofia da linguagem burguesa. Ele desnuda o escamoteamento burguês ao revelar que o signo dominante origina-se a partir do horizonte social que a classe burguesa ocupa na totalidade histórica do sistema capitalista. A pretensão dos ideólogos burgueses é a de falar de um ponto neutro, universal, abstrato, puro, racional. Eles não reconhecem que aquilo que produzem (no caso de nossa pesquisa, o currículo) diz respeito à disputa classista do signo - valorado conforme as condições psicoideológicas de cada classe.

Assim, sem fazer uso da dialética, os ideólogos da burguesia, pertencentes à orientação do objetivismo abstrato, querem arbitrar a unicidade do signo de forma sincrônica, sem reconhecer as suas contradições (diacronias). A expressão mais explícita deste engessamento se encontra na prisão da palavra em um dicionário a fim de matar o seu processo social, plurivalente, vivo e móvel. Com o mesmo sentido ideológico, mas noutro bloco, os também ideólogos burgueses, de orientação subjetivista idealista, defendem que a significação depende unicamente da psicologia individual criativa. Ambas as posições, aparentemente contraditórias, concordam entre si numa coisa: os signos não dependem do horizonte social (determinado período histórico e determinado grupo social) que compõe o contexto no qual eles ganham as suas significações de forma contraditória.

Com isto Bakhtin revela o que toda a classe dominante quer esconder, ou seja, a particularidade do discurso que pretensamente é apresentada como universal. Bakhtin revela o prisma do meio social concreto que engloba a burguesia e forma o horizonte social desde onde ela interpreta a cidade e o mundo (cf. BAKHTIN, 2006, p. 114-115). Ao contrário da pretensa "consciência global", ou da "consciência transcendental", ou do "sujeito puramente gnosiológico" kantiano (cf. BAKHTIN, 2006, p. 54), ou da "gramática universal" de Leibniz, ou da inocência do cogito cartesiano (cf. BAKHTIN, 2006, p. 83)... Bakhtin demonstra a base material na qual estão situados os pronunciamentos destes filósofos e de suas filosofias. 
Bakhtin, ao ressaltar a luta de classes pela valoração do signo dentro de uma totalidade histórica formada por diferentes horizontes sociais, chama a atenção para aquilo que se encontra no contexto do texto. Ele demonstra que um signo - uma palavra, por exemplo - não faz qualquer sentido sem a compreensão de seu contexto "o sentido da palavra é totalmente determinado por seu contexto. De fato, há tantas significações possíveis quantos contextos possíveis" (BAKHTIN, 2006, p. 107-108).

Com isto Bakhtin não pretende desagregar a palavra, pelo contrário, conserva a sua unicidade (sincronia), porém, juntamente com esta, salva a sua polissemia de forma dialética (diacronia). 0 que ele não aceita é o objetivismo abstrato do filólogo-linguista que aparta a palavra de seu contexto, matando a sua dinamicidade viva e complexa a fim de normatizá-la, estabilizá-la e congelá-la no dicionário. Este recorte unilateral da realidade mais ampla da palavra cria uma ficção que não corresponde mais à realidade da palavra, manipulando-a de acordo com os interesses dominadores.

Assim, a chance de superar a manipulação universalizante da palavra se encontra na possibilidade de compreendê-la dialeticamente, ou seja, compreender as oposições nos contextos de uma palavra.

Pode-se, no entanto, dizer que toda enunciação efetiva, seja qual for a sua forma, contém sempre, com maior ou menor nitidez, a indicação de um acordo ou de um desacordo com alguma coisa. Os contextos não estão simplesmente justapostos, como se fossem indiferentes uns aos outros; encontram-se numa situação de interação e de conflito tenso e ininterrupto (BAKHTIN, 2006, p. 109).

Por conta desta relação social conflitiva (e não justaposição) entre os contextos é que se torna necessário preservar a unicidade da palavra (fonética, gramática, léxico, significação...), sem a qual a compreensão entre os grupos sociais seria impossível. Mais uma vez Bakhtin advoga a favor da posição dialética que compreende os opostos (diacrônico $X$ sincrônico; polissemia $X$ unicidade; fala $X$ sistema linguístico; liberdade $X$ necessidade) em sua unidade tensa e sintética. 
Bakhtin ilustra esta relação através de um exemplo no qual trabalha com a palavra "fome". Esta necessidade natural é, em sua totalidade, uma expressão socialmente dirigida e determinada por uma situação precisa na qual os participantes conferem forma ao enunciado. Conforme o contexto tal palavra poderá ressoar como exigência, solicitação, pedido rebuscado, simples, seguro, tímido, etc.

Contra a posição subjetivante que conferia condições especiais ao enunciado concebido "na alma", Bakhtin o reconhece como o estágio inicial de seu desenvolvimento, porém não isento das características sociais, uma vez que estas implicam na atividade mental da mesma forma que incidem sobre a objetividade exterior. Portanto, a sensação de "fome" não dispensa a sua expressão ideológica, sempre presente na consciência (discurso interior) na forma de súplica, raiva, lamentação, indignação... além de outras entonações interiores mais sutis e complexas. Desta forma, o discurso interior desde sempre estará marcado pelo julgamento social sobre a fome e o faminto, os interlocutores (sujeitos e/ou grupos sociais) para os quais a consciência e a sensação da fome se dirigem. Por isto a sensação interior da fome é marcada pela situação imediata em que é percebida e pela situação social do faminto que a torna tão variada quanto são variados os contextos que lhe dão origem:

Pode-se descrever a fome, acrescentando-se um apelo à revolta, à agitação; nesse caso a atividade mental será estruturada em função de um apelo potencial, a fim de provocar a agitação; a tomada de consciência pode tomar a forma do protesto, etc. (BAKHTIN, 2006, p. 117).

Por conta desta orientação social das sensações, percepções, discursos internos e externos é que a fome humana diferencia-se da mera fome fisiológica dos animais. Esses, ao contrário dos humanos, apenas emitem grunhidos sem se dirigir ideologicamente a um interlocutor. A atividade mental humana oscila entre a atividade mental do eu e a atividade mental do nós. Sem a primeira o sujeito perderia a sua subjetividade, sem a segunda não conseguiria realizar suas representações verbais para a sociedade na qual se encontra. Bakhtin mantém a tensão destes dois pólos e reconhece a sua unidade, uma vez que quanto mais socialmente enraizada for a consciência individual tanto mais fortalecida ela haverá de se tornar. Ou seja, "quanto mais forte, mais bem 
organizada e diferenciada for a coletividade no interior da qual o indivíduo se orienta, mais distinto e complexo será o seu mundo interior" (BAKHTIN, 2006, p. 117).

Como resultado deste processo Bakhtin oferece uma série de exemplos. Um mendigo, sem classe, isolado, desorganizado terá uma atividade mental específica dentro dos limites determinados pela sua condição social-ideológica, tais como, resignação, protesto individualista, vergonha, sentimento de dependência... que povoarão a sua atividade mental. Diferente deste seria um faminto (um camponês, por exemplo) pertencente a uma coletividade sem vínculos materiais, sem economia comum, tal como ocorre nas localidades onde cada membro se encontra no mundo fechado de sua propriedade. Neste caso, se todos viessem a passar fome por conta de algum acidente natural e todos viessem a passar fome certamente os indivíduos não sentiriam vergonha de sua situação, nem se sentiriam humilhados como o mendigo, uma vez que a sua condição não é percebida como única e exclusiva, gerando no máximo uma consciência fatalista e resignada.

Outra situação seria originada pelos integrantes de uma comunidade com vínculos materiais objetivos (a classe para si - por exemplo) na qual a resignação dará lugar à atividade mental do protesto ativo e seguro.

Com isto Bakhtin demonstra que

Todos os tipos de atividade mental que examinamos, com suas inflexões principais, geram modelos e formas de enunciações correspondentes. Em todos os casos, a situação social determina que modelo, que metáfora, que forma de enunciação servirá para exprimir a fome a partir das direções inflexivas da experiência (BAKHTIN, 2006, p. 119).

Por isso, os diferentes posicionamentos ideológicos são dependentes das atividades mentais do nós que ocorrem na atividade mental do eu, desde sempre situado socialmente. Na avaliação de nosso autor o terceiro exemplo (da classe para si) demonstra um maior e bem formado desenvolvimento ideológico da atividade mental, uma vez que este comporta dados sociais mais amplos que os exemplos precedentes (do mendigo e do camponês). 
Como consequência direta desta concepção Bakhtin pode denunciar a concepção burguesa da atividade mental individualista como falsa, uma vez que também esta concepção se encontra orientada por uma determinada e sólida concepção social. Para Bakhtin o individualismo não é fruto da atividade mental do eu, mas sim da atividade mental do nós criado pela burguesia. A posição sócio-econômica individualista do capitalista gera a consciência dos valores individualistas, encontrando a sua fonte primeira no modo de vida social inaugurado pelo capitalismo e não na suposta condição universal comum a todo ser humano.

Com isto conclui-se que não há, por mais que os ideólogos da burguesia o neguem, a linguagem que não esteja situada num horizonte social concreto. Deste modo, Bakhtin inaugura a concepção materialista da linguagem, pautada no horizonte social, capaz de fundamentar a construção curricular incapaz de compactuar com a pseudouniversalidade da filosofia da linguagem burguesa.

\section{CONCLUSÃO}

Após o caminho percorrido do signo ao horizonte social e deste à crítica de sua negação realizada pela burguesia - que apresenta os seus signos como universais - é possível pontualizar algumas conclusões provisórias.

Bakhtin desenvolve uma filosofia da linguagem marxista capaz de superar todos os dualismos presentes nas discussões sobre a linguagem utilizando-se para isto da dialética, que não suprime os opostos, mas que, conservando-os, eleva-os a outro patamar no qual se mantêm como opostos, mas também encontram a sua coincidência e estabelecem interpenetrações. $O$ pai de todos estes dualismos na linguagem, segundo o autor, é formado pelas posturas extremo-opostas do subjetivismo individualista e do objetivismo abstrato.

Tal síntese dialética não cede à tentação das posições sincréticas de justaposições, mas sim na superação da tese e da antítese que lhe deram origem. Como expressão visível desta síntese Bakhtin estabelece o signo como o princípio sintético por excelência da relação dialética. No signo subjetividade e objetividade estão presentes, sempre mediados pelo horizonte social, a partir do qual cada grupo/sujeito, ideologicamente, o disputa. 
Bakhtin situa a linguagem, da qual o signo é a expressão sintética (e a palavra, pela sua versatilidade, a melhor representante), num horizonte social. Neste a linguagem se origina, para ele tende e a partir dele é compreendida. Com isso, Bakhtin consegue ser coerente com os pressupostos do materialismo inaugurado por Marx, que toma a atividade social dos seres humanos como construtora da realidade material. Assim, afirmar a existência de um alcance e um limite para a linguagem equivale situá-la no horizonte social da materialidade histórico-concreta.

Para Bakhtin o próprio signo carrega consigo a tensa relação sócio-histórica-econômica que lhe dera origem. Ou seja, a definição da linguagem (do signo, da palavra...) não é dado por elementos estritamente linguísticos, mas sim de forma mais ampla, uma vez que dependem da totalidade histórica na qual se encontra o horizonte social originário. Por consequência, o signo testemunha em seu corpo as transformações sócio-econômicas ocorridas na história.

Assim, todo signo traz consigo os valores instituídos pelas sociedades, tempos históricos, modelos econômicos, classes sociais, interlocutores concretos que os originaram. Isto que se diz do signo pode ser aplicado à linguagem como um todo, à palavra e por consequência, também aos discursos sobre o currículo.

Embasados na concepção marxiano-bakhtiniana é possível construir um arsenal crítico capaz de combater a pretensa universalidade neutra, naturalizada, abstrata da filosofia da linguagem burguesa que esconde o "horizonte social" de suas palavras e signos em geral. Por mais que os ideólogos burgueses não queiram, seus discursos são situados num modelo econômico, num tempo histórico e numa classe social. Por isso, o alcance de suas falas não pode ser (e não é) considerado, numa perspectiva crítica, como universais. Elas nascem, reproduzem-se e resolvemse num horizonte social concreto, material bem definido que determina o que será abordado e o que será silenciado.

Por isso, pode-se afirmar que somente os discursos pronunciados de acordo com o horizonte social da linguagem poderão superar a pretensa universalidade burguesa na construção curricular. Aquilo que o discurso burguês quiser esconder sob o véu da neutralidade poderá ser desnudado ao se mostrar o horizonte social que lhe deu origem. Com isso, os currículos tecnicistas, conservadores, alinhados com o capitalismo (o mercado, o agronegócio, as multinacionais...) mostraram o que 
pretendem esconder, a saber, os interesses de classe que defendem, mantém, reproduzem e a serviço dos quais pretende formar as pessoas.

Além disso, a linguagem do discurso curricular, ao tomar para si os horizontes sociais da classe dominada em luta pela sua libertação, irá edificar propostas curriculares que serão a expressão da negatividade dialética do macrossistema, contra-hegemônicas à totalidade histórica construída pelo capitalismo.

\section{REFERÊNCIAS}

BAKHTIN, Mikhail. Marxismo e filosofia da linguagem: problemas fundamentais do método sociológico na ciência da linguagem. 12. ed. São Paulo: HUCITEC, 2006.

CRUZ, Antônio. A janela estilhaçada: a crise do discurso do novo sindicalismo. Rio de janeiro: Vozes, 2000.

GADAMER, Hans-Georg. Verdade e método: Traços fundamentais de uma hermenêutica filosófica. 3. Ed. Petrópolis: Vozes, 1999.

MARX, Karl. O Capital: Crítica da Economia Política. 2. ed. São Paulo: Nova Cultural, 1985. 1.v. (col. Os economistas).

. A Questão Judaica. Disponível em: <http://www.lusosofia.net>. Acesso em: 10 set. 2008.

. Manuscritos Econômico-Filosóficos. São Paulo: Martin Claret, 2001.

. A Miséria da Filosofia. 2. ed. São Paulo: Global, 1985.

Para à Crítica da Economia Política: Prefácio. Disponível em: <http://www.marxists.org/portugues/marx/ 1859/01/prefacio.htm>. Acesso em: 1 ago. 2009.

; ENGELS, Friedrich. A Ideologia Alemã (I- Feuerbach). 4. ed. São Paulo: Editora Hucitec, 1984.

MÉSZÁROS, István. Educação para além do Capital. São Paulo: Boitempo, 2005.

SILVA, Tomaz Tadeu da. Documentos de identidade: uma introdução do currículo. 3. ed. Belo Horizonte: Autêntica, 2010. 